2015

\title{
Relationship between physical capacity and match performance in semiprofessional
}

\section{Australian rules football}

Ben G. Piggott

University of Notre Dame Australia, benjamin.piggott@nd.edu.au

Michael R. McGuigan

Michael J. Newton

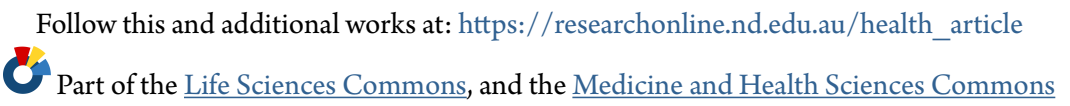

This article was originally published as:

Piggott, B. G., McGuigan, M. R., \& Newton, M. J. (2015). Relationship between physical capacity and match performance in semiprofessional Australian rules football. Journal of Strength and Conditioning Research, 29 (2), 478-482.

http://doi.org/10.1519/JSC.0000000000000765

This article is posted on ResearchOnline@ND at

https://researchonline.nd.edu.au/health_article/128. For more

information, please contact researchonline@nd.edu.au.
THE UNIVERSITY OF 9a. NOTRE DAME $\begin{array}{lllllllll}A & \text { U S } & \text { T } & R & A & \text { L } & \text { I A } & \text { A }\end{array}$ 
This is the author's post-print copy of the article published as:

Piggott, B. G., McGuigan, M. R., \& Newton, M. J. (2015).

Relationship between physical capacity and match performance in semiprofessional Australian rules football. Journal of Strength and Conditioning Research, 29(2), 478-482. doi: $10.1519 /$ jsc.0000000000000765 
The relationship between physical capacity and match performance in semi-professional Australian Rules Football 


\section{ABSTRACT}

This study investigated the relationship between physical performance and match performance in Australian Rules Football (ARF). Thirty-six semi-professional ARF players participated in this study. Physical capacity was measured using a $3 \mathrm{~km}$ time trial. Match performance was measured throughout the 2013 season via two methods; direct game involvements (DGI) per minute and a recording of coaches' vote post game. The main finding of the study was that 3 $\mathrm{km}$ time trial performance was a significant predictor of DGI per minute $(p<0.05)$. In addition, the number of senior games played was also significant in predicting DGI per minute $(p<0.05)$. Furthermore, the number of senior games significantly correlated with coaches' votes $(p<0.05)$. There were no significant relationships between $3 \mathrm{~km}$ time trial and coaches' vote. The results highlight the importance of developing physical capacity in the pre-season period; the players who were better performers in the $3 \mathrm{~km}$ time trial had a greater number of DGl's per minute. This information is important to consider in pre-season planning to ensure sufficient time is dedicated to developing physical capacity in the training program, as it is directly associated with performance. In addition, this research also highlights the importance of playing experience in relation to team selection. Playing experience, as measured by the number of senior games played, had a significant relationship with both measures of match performance.

Key words: 3 km time trial; Game involvements, Coaches' vote; Team sport. 


\section{INTRODUCTION}

Australian Rules Football (ARF) is a field-based team sport that requires high-intensity, intermittent exercise including many intense bursts of activity (14). Each team comprises 22 players with 18 on the field at any one time. A game consists of 4 quarters of actual playing time with breaks following each quarter. Western Australian Football League (WAFL) is a state based competition consisting of 9 teams who participate in 23 round games followed by a final series for teams that finished in the top 4. Players are semi-professional and typically train 3-4 times per week and play on weekends.

Sports performance can be viewed and measured in a number of different ways. This can include selection in a specific team (team selection), number of games played at a specific level (career success), subjective voting by coaches after performance (coaches' votes) and measurements of physical indices and/or game contributions during competitions (match performance). Studies have investigated the relationship between physical fitness capabilities and career success, team selection or playing status in variety of sports $(3,7,10,12,13,19,21$, 22). 
In elite junior basketball, Hoare (7) conducted research involving predicting success with junior players from physiological and anthropometric profiles. The conclusion was the 'best' players could be distinguished from the 'rest' players on a number of anthropometric and physiological variables (speed, agility, vertical jump, basketball throw, and aerobic endurance). In America's National Football League (NFL), major differences were observed with the 40-yard dash, vertical jump, pro-agility shuttle and the 3-cone drill between drafted and non-drafted players in the skill players' group (19). In junior handball, elite players scored significantly better on strength, speed and cardiorespiratory endurance (13).

Specific to ARF, Le Rossignol et al. (12) found that total repeated-sprint time differed significantly between those selected and those not selected in the first competition game of the season in professional Australian Football League (AFL). Keogh (10) showed that selected players in elite $U / 18$ state based competition were significantly taller and had greater upper body strength than players who were not selected. In another study investigating elite under eighteen (U/18) players, Woods et al. (21) concluded that the combination of standing height, dynamic vertical jump off the non-dominant foot and the multistage fitness test were the strongest predictors of playing status in this cohort of WAFL players. Young et al. (22) investigated physiological and anthropometric characteristics of starters and non-starters in an elite ARF Club. They reported that the starters selected to play the first game of the season performed significantly better in measures of leg power, spring speed, and distance covered in 
the Yo-Yo intermittent recovery test compared to non-starters. Burgess et al. (3) concluded that superior performance in \% sprint and sprints per minute in game play, combined with speed assessed at National Draft Camp $(5 \mathrm{~m}, 10 \mathrm{~m} \& 20 \mathrm{~m})$ were the best predictors of career success in elite U/18 ARF players.

A recent area of interest amongst sports scientists and strength and conditioning coaches involves exploring the relationship between measures of physical fitness and anthropometric parameters and actual match performance $(2,4,5,11,12,18,23)$. This has important implications because it can potentially provide further insights into the most important physical capacities that need developing for optimal playing performance. Although physical fitness and anthropometric measures are believed to be related to playing performance, there is limited data that describes this relationship (23).

Studies have reported on physical fitness capacity and the effect this has have on match performance in a variety of sports $(2,4,5,11,18,23)$. Castagna et al. (4) investigated the link between subject results in Yo-Yo IR1 test and physical match performance in young male soccer players. They concluded that specific endurance, as determined by Yo-Yo Intermittent Recovery Level 1 (IR1) performance, positively affects physical match performance. Rampinini et al. (18) found that elite professional soccer players who performed better on repeated sprint tests were able to record greater distances at higher speeds of running and sprinting in matches. In 
further work with soccer, Helgerud et al. (6) found that enhanced aerobic endurance in soccer players improved match performance where soccer performance was measured by distance covered, work intensity, number of sprints and involvements with the ball during a match. In the sport of rugby league, Gabbett and Seibold (5) showed that well-developed lower-body strength was associated with better running and repeated-effort performance during match play. Furthermore, they found that improvements in lower-body strength may facilitate greater running and repeated high-intensity effort work rates in semi-professional rugby league players. Krustrup and Bangsbo (11) also reported that the Yo-Yo intermittent recovery test can be used to evaluate top class referees' performance in soccer.

Specific to ARF, there is a developing body of literature investigating how physical capacity measures relate to match performance $(12,15,23)$. Mooney et al. (15) investigated if Yo-Yo Intermittent Recovery Level 2 (IR2) results were linked to ARF performance in professional players. They found a significant direct relationship between Yo-Yo IR2 and number of ball disposals and this was mediated through increased high-speed running ( $>15 \mathrm{~km} / \mathrm{kr}$ ). Young and Pryor (23) found that shorter and lighter players who possess high levels of speed and endurance are more likely to acquire possessions and be awarded votes in an elite $U / 18$ competition. They also showed that hand span, agility and flexibility were not related to performance indicators. 
There has been no research that has directly investigated the relationship between physical capacity and match performance in semi-professional ARF. Therefore, the purpose of this study was to investigate the relationship between a $3 \mathrm{~km}$ time trial and match performance in a statebased ARF game.

\section{METHODS}

\section{Experimental Approach to the Problem}

A prospective design was employed in this study to examine the relationship between physical capacity and performance. Physical capacity (reflected in $3 \mathrm{~km}$ time trial) and match performance (reflected by DGI per minute and coaches' vote) were gathered on participants over the 2013 season. A sample was determined as a $3 \mathrm{~km}$ time trial score and match performance scores attributed to the one player. Informed consent was gathered from participants prior to the commencement of the study.

\section{Subjects}

Thirty-six male ARF players were participants in this study (height $1.84 \pm 0.08 \mathrm{~cm}$; mean \pm SD; weight $84.0 \pm 9.5 \mathrm{~kg}$, sum of 7 skinfolds $57.6 \pm 11.0 \mathrm{~mm}$ ). Skinfolds were recorded using seven sites (triceps, biceps, subscapular, supraspinale, abdomen, thigh and calf) and were measured by an accredited Sports Dietician (Australia). Participants recruited for the study ranged in age from 19 - 30 years and all were team members of a West Australian Football League (WAFL) 
Club. Five of the subjects had played professional AFL previously, whilst two others had represented the Western Australian State Senior team which is selected from all 9 semiprofessional WAFL Clubs. Ethical approval was obtained by the University Research Ethics Committee and informed consent was obtained from participants.

\section{Procedures}

\section{$3 \mathrm{Km}$ Time Trial}

As part of the 13 week pre-season program, players underwent a series of $3 \mathrm{~km}$ time trials in preparation for the upcoming season.

Trials were held on a grass surface and all administered at the same time of day ( $5.45 \mathrm{pm})$ after a 10 minute warm up; this procedure was repeated for each test. Players were notified of the upcoming testing session the week prior to each test. Players were advised to ensure they refrained from strenuous physical activity two days prior to testing and to also ensure adequate hydration practices were followed. The track was measured using a trundle wheel. A total of 4 trials were held over pre-season period; one on the first day of pre-season, one after 5 weeks of training (in last week before Christmas break), another two weeks later (in the first week back after Christmas break) and a final test in last week of pre-season training before trial games begin. The subjects' performance in their final $3 \mathrm{~km}$ time trial was used in the sample for analysis. Pyne and Cormack (17) reported a typical error of 24 seconds in a $3 \mathrm{~km}$ time trial 
(mean time reported $11: 20 \mathrm{~s} \pm 0.45$ therefore $\mathrm{TE}=3.5 \%$ ). The $3 \mathrm{~km}$ time trial was selected to use as a measure of physical capacity for two reasons. Firstly, it is used by the AFL at Draft Combine, the peak body of junior elite testing in ARF. The results from Draft Combine are also made available to the public; hence comparisons can be made between semi-professional athletes and junior elite. Secondly, the $3 \mathrm{~km}$ time trial is a relatively time efficient test to complete. Being efficient with time is an essential requirement in pre-season training in a semiprofessional ARF environment as there are large numbers of players completing tests. There are also demands with time from coaches to complete skill and tactical sessions.

\section{Match Performance}

Match performance was measured in two ways:

\section{Direct Game Involvement}

Each subject's direct game involvements (DGI) were recorded by a commercial statistical analytics company (Champion Data, South Bank, Australia). Champion Data is widely used in ARF and provide statistics for professional AFL games and as well all major sub-elite competitions. DGI included number of kicks, handballs, marks and tackles made in matches. Testing has shown 99\% accuracy when using Champion Data statistics (16). In addition, Champion Data statistics have been used in previous published research $(9,15)$. DGI per minute was used as there was a combination of both senior and reserve grade games used in the data 
set which have different duration in total game times. In addition, the WAFL has an unlimited interchange policy where players can rotate on and off the field with no set cap on total number of rotations. Hence all participating players will have different playing times; that is the time that players were on the field and not on the interchange bench. To standardise results, all players' DGI were divided by playing time of that specific player. Playing minutes were calculated using "Player Tracker" software which was specifically developed for this WAFL Club.

\section{Coaches' Vote}

Votes were awarded by a match committee and this occurred 45 minutes post game. Four coaches (senior coach and three zone coaches - defensive, midfield and forwards') voted using a scale of 1-10 where 10 is considered the "Perfect Game". A maximum of 8 players can receive votes from each coach. The maximum votes that a player could receive for a game from all coaches combined is 40 votes; that is each coach giving a player a score of "10". Professional development sessions were held at the start of the season with the football manager and all coaching staff to ensure validity and reliability of these scores.

Coaches' votes as a measure of match performance has been used in previous research (15, 23). Mooney et al. (15) used coaches' votes as a measure in their research stating the score was used to quantify the player's subjective performance which encompasses both tactical and technical performance. 


\section{Statistical Analyses}

Statistical analysis was performed using SPSS (Version 22). Data has been reported as Mean \pm SD. A total of 163 samples were obtained in the study comprising of 136 senior grade games and 44 reserve grade games. Regression using linear mixed models was used to analyse the data. Linear mixed models are suitable for longitudinal data where multiple measures are repeatedly taken from individuals. Statistical significance was set at $p<0.05$. Age and number of Senior Games were contributing factors that were controlled for in the regression model.

\section{RESULTS}

Mean values of variables used in the regression model are shown in Table 1.

INSERT TABLE 1 ABOUT HERE

There was a significant association between $3 \mathrm{~km}$ time trial and DGI per minute $(p<0.05$, $t=-3.829)$. There was also a significant association between number of senior games played and DGI per minute $(p<0.05, \mathrm{t}=2.757)$. There was no significant association between age and DGI per minute. The summary of this regression model is shown in Table 2. 
INSERT TABLE 2 ABOUT HERE

The number of senior games played had a significant association with coaches' votes $(p<0.05$, $t=1.999)$. There was no significant association between $3 \mathrm{~km}$ time trial and coaches' votes or age and coaches' votes $(p<0.05)$. The summary of this regression model is shown in Table 3 .

INSERT TABLE 3 ABOUT HERE

\section{DISCUSSION}

The main finding of this study was that $3 \mathrm{~km}$ time trial performance was a significant predictor of DGI per minute. In addition, the number of senior games played was also a significant in predictor of DGI per minute. Furthermore, the number of senior games significantly correlated with coaches' votes. These results are important for strength and conditioning coaches to consider as it is imperative to identify and highlight the contributing factors to individual match performance. 
There is a body of research involving elite professional $\operatorname{ARF}(8,12,14,15,22)$ and also research $\mathrm{U} / 18 \operatorname{ARF}(3,10,21,23)$. However, there is a limited amount of literature involving semiprofessional ARF and this study will contribute to this body of research. The results of this study will assist coaching staff in highlighting the importance of physical capacity in determining match performance in a semi-professional ARF environment. This study is unique in that it focused on whether successful semi-professional players in ARF (in terms of match performance) were also the better performers in pre-season physical capacity.

The findings agree with previous literature on ARF, suggesting a relationship exists between measures of physical capacity and match performance $(4,5,15,18,23)$. Young and Pryor et al. (23) found that players in an elite U/18 ARF competition, who had a greater number of possessions (kicks and handballs), were significantly faster over 5 and $20 \mathrm{~m}$ and produced higher predicted V02 max values $(E S=0.55)$. Having greater pre-season levels of speed and endurance have been shown to be advantageous for gaining possessions (23). Mooney et al. (15), investigating elite ARF, found a significant direct relationship between Yo-Yo IR2 and number of ball disposals which was mediated through increased high-speed running (>15 $\mathrm{km} / \mathrm{kr})$. 
A point of interest in this research is the strength of the association between $3 \mathrm{~km}$ time and DGI per minute. The regression result, although significant, showed a relatively small association. Part of the reason, could be the choice of $3 \mathrm{~km}$ time trial as test of physical capacity. It could be argued that the $3 \mathrm{~km}$ time trial is not as relevant as it once was in ARF due to game developments and rule changes. Wisbey et al. (20) showed that the typical AFL player at elite level covers $\sim 12 \mathrm{~km}$ in total distance per game, and comprises $\sim 240$ moderate accelerations and $\sim 10$ rapid accelerations per game. Rule changes in recent seasons have increased the speed of the game. Hence, increases in the physical demands of ARF football were evident between 2005 and 2008 and this has significant implications for coaching staff (20). Le Rossignol et al. (12) state that the physical demands of Australian football have increased over recent seasons and players require high levels of aerobic power and an ability to perform short bursts of high-intensity efforts.

One of the implications for strength and conditioning coaches is to ensure the tests used to measure physical capacity in pre-season are relevant to game requirements. The strength of the association between physical capacity and match performance could possibly be stronger if a more suitable test, such as the Yo-Yo IR2 recently used by other researchers (15), was used to measure physical capacity. The Yo-Yo intermittent recovery tests evaluate an individual's ability to repeatedly perform intense exercise (1). It could be argued, that recent rule changes have increased physical demands of AFL Football and the $3 \mathrm{~km}$ time trial is not as relevant a 
measure of physical capacity as it has been in previous years. Further research is needed to confirm this theory.

The number of senior games played directly reflects playing experience. There were significant associations between senior games played and both measures of match performance, DGI per minute and coaches' votes. These findings support previous research that has investigated the effect of playing experience on match performance. Young et al. (22) found that players selected as starters in the first game of the season were significantly older and more experienced. Furthermore, Mooney et al. (15) reported that greater playing experience was also found to strengthen the relationship between high intensity running and number of ball disposals. Mooney et al. (13) suggested that the more experienced players can read the play more effectively, and place themselves in a more appropriate position to receive the ball and / or are more likely to be able to beat an opponent in a one-on-one contest.

A limitation to be acknowledged in this study concerns the use of the coaches' vote as measure of match performance. The researchers did not have access to individual coach data which prevented analysis on the level of agreement amongst coaches. 


\section{PRACTICAL APPLICATIONS}

For strength and conditioning coaches, the results highlight the importance of developing physical capacity in the pre-season period. Players that run a faster $3 \mathrm{~km}$ time trial had a greater number of DGI per minute. This association is important information for the strength and conditioning coach to communicate with players, as it could provide the testing with more relevance to game play involvements. For the players, this research also highlights the importance of training to develop physical capacity as is significantly related to individual match performance. It is also important information to consider when the team coach and strength and conditioning coach plan the pre-season program, so as to ensure sufficient time is allocated to develop physical capacity, as it is directly associated with performance. Physical capacity can be developed by a variety of methods including aerobic endurance sessions, interval training, skills based conditioning games and appropriately planned skill drills. The second practical application of this study is relevant for the team coach who is in charge of player selection for games. Playing experience, as measured by number of senior games played, had a significant relationship with both measures of match performance and should be taken into account when team selection occurs. 


\section{REFERENCES}

1. Bangsbo J, laia FM, and Krustrup P. The Yo-Yo intermittment recovery test. Sports Medicine 38: 37-51, 2008.

2. Bradley PS, Carling C, Gomez D, Hoode P, Barnes C, Ade J, Boddy M, Krustrupi P, and Mohri M. Match performance and physical capacity of players in the top three competitive standards of English professional soccer Human Movement Science 32: 808-821, 2013.

3. Burgess D, Naughton G, and Hopkins W. Draft-camp predictors of subsequent career success in the Australian Football League Journal of Science and Medicine in Sport 15: 561-567, 2012.

4. Castagna C, Impellizzeri FM, Cecchini E, Rampinini E, and Alvarez B. Effects of intermittent-endurance fitness on match performance in young male soccer players. Journal of Strength and Conditioning Research 23: 1954-1959, 2009.

5. Gabbett TJ and Seibold AJ. Relationship between tests of physical qualities, team selection, and physical match performance in semi-professional rugby league players. Journal of Strength and Conditioning Research 27: 3259-3265, 2013.

6. Helgerud J, Engen LC, Wisloff U, and Hoff J. Aerobic endurance training improves soccer performance. Medicine \& Science in Sports \& Exercise 33: 1925-1931, 2001.

7. Hoare DG. Predicting success in junior elite basketball players - the contribution of anthropometric and physiological attributes. Journal of Science and Medicine in Sport 3: 391-405, 2000.

8. Johnston RJ, Watsford MJ, Pine MJ, Spurrs RW, Murphy A, and Pruyn EC. Movement demands and match performance in professional Australian football. International Jounral of Sports Medicine 33: 89-93, 2011.

9. Johnston RJ, Watsford ML, Pine MJ, Spurrs RW, Murphy A, and Pruyn EC. Movement demands and match performance in professional Australian Football. International Journal of Sports Medicine 33: 89-93, 2012.

10. Keogh J. The use of physical fitness scores and anthropometric data to predict selection in an elite under 18 Australian rules football team. Journal of Science and Medicine in Sport 2: 125-133, 1999. 
11. Krustrup $\mathrm{P}$ and Bangsbo J. Physiological demands of top-class soccer refereeing in relation to physical capacity: effect of intense intermittent exercise training Medicine \& Science in Sports \& Exercise 19: 881981, 2001.

12. Le Rossignol P, Gabbett TJ, Comerford D, and Stanton WR. Repeated-sprint ability and team selection in Australian football league players. International Journal of Sports Physiology and Performance 9: 161-165, 2014.

13. Mohamed H, Vaeyens R, Matthys S, Multael M, Lefevre J, Lenoir M, and Philippaerts R. Anthropometric and performance measures for the development of a talent detection and identification model in youth handball. Journal of Sports Sciences 27: 257-266, 2009.

14. Mooney M, Cormack SJ, O'Brien B, and Coutts AJ. Do physical capacity and interchange rest periods influence match exercise-intensity profile in Australian football? International Journal of Sports Physiology and Performance 8: 165-172, 2013.

15. Mooney M, O'Brien B, Cormack SJ, Coutts AJ, Berry J, and Young W. The relationship between physical capacity and match performance in elite Australian football: a mediation approach. Journal of Science and Medicine in Sport 14: 447-452, 2011.

16. O'Shaughnessy DM. Possessions versus position; strategic evaluaiton in AFL. Journal of Science and Medicine in Sport 5: 533-540, 2006.

17. Pyne DB and Cormack SJ. Physiological Tests for Elite Athletes.: Human Kinetics, 2013.

18. Rampinini E, Bishop D, Marcora SM, Ferrari Bravo D, Sassi R, and Impellizzeri FM. Validity of simple field tests as indicators of match-related physical performance in top-level professional soccer players. International Journal of Sports Physiology Performance 28: 228-235, 2007.

19. Sierer SP, Battaglini CL, Mihaili JP, Shields EW, and Tomasini NT. The National Football League combine: performance differences between drafted and nondrafted players entering the 2004 and 2005 drafts. Journal of Strength and Conditioning Research 22: 6-12, 2008. 
20. Wisbey B, Montgomery PG, Pyne DB, and Rattray B. Quantifying movement demands of AFL football using GPS tracking. Journal of Science and Medicine in Sport 13: 531-536, 2010.

21. Woods CTE, Raynor AJ, Bruce L, McDonald Z, and Collier N. Predicting playing status in junior Australian Football using physical and anthropometric parameters. Journal of Science and Medicine in Sport, 2014.

22. Young WB, Newton RU, Doyle TLA, Chapman D, Cormack S, Stewart G, and Dawson B. Physiological and anthropometric characteristics of starters and non-starters and playing positions in elite Australian Rules football: a case study. Journal of Science and Medicine in Sport 8: 333-345, 2005.

23. Young WB and Pryor L. Relationship between pre-season anthropometric and fitness measures and indicators of playing performance in elite junior Australian Rules football. Journal of Science and Medicine in Sport 10: 110-118, 2007.

\section{ACKNOWLEDGEMENTS}

The authors would like to thank East Fremantle Football Club for its permission and cooperation in allowing this study to take place. There was no external funding provided by any organization for this study. 